\title{
WARMING THE OXYGEN WITH THE RESCUER'S BODY AS A POSSIBLE METHOD OF HEAT LOSS PREVENTION IN A PREHOSPITAL SETTING. INITIAL REPORT
}

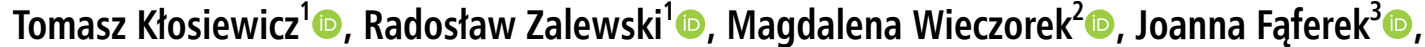 \\ Maciej Sip ${ }^{1}$, Leszek Różański ${ }^{\circledR}$, Ewa Stachowska ${ }^{2}$ \\ 'Department of Medical Rescue, Faculty of Health Sciences, Poznan University of Medical Sciences, Poznan, Poland \\ ${ }^{2}$ Department of Metrology and Measurement Systems, Faculty of Mechanical Engineering, \\ Poznan University of Technology, Poznan, Poland \\ ${ }^{3}$ Medical Education Department, Faculty of Medicine, Jagiellonian University Medical College, Krakow, Poland
}

\begin{abstract}
INTRODUCTION: Discomfort from cold is a significant problem for trauma victims. Prehospital treatment of a hypothermic patient is hugely challenging for medical rescue teams. Preventing heat loss is a basic treatment in all levels of care. The main aim objective of this report was to examine the influence of low ambient temperature on cooling oxygen in a rescue set and to check whether heating the oxygen tube with the rescuer's body is a legitimate method.
\end{abstract}

MATERIAL AND METHODS: In the control test, an oxygen tube was disposed of across a styrofoam board, whereas a study group was an oxygen tube hidden underneath the paramedic's jacket. A thermographic camera was used to define oxygen's temperature in different parts of the medical setting. The research was carried out in the winter season in the natural environment, which was comparable to the regular work conditions of the services.

RESULTS: In a control group, the oxygen temperature in an oxygen mask was similar to the ambient temperature. This research has found that warming up an oxygen tube underneath the paramedic's jacket resulted in a 12.9 degree increase in temperature in an oxygen mask.

CONCLUSIONS: Keeping the oxygen tube underneath a jacket may serve as an additional method of preventing patients' heat loss. The authors express the need for further research on providing hypothermic patients with warm oxygen. The authors believe that introducing such an easy method of warming up the oxygen may positively influence treatment results and give rise to a discussion on the presented method.

KEY WORDS: oxygen inhalation therapy, hypothermia, emergency medical services

Disaster Emerg Med J 2021; 6(3): 137-143

\section{INTRODUCTION}

One of the basic conditions for maintaining homeostasis is the ability to maintain a constant body temperature. Hypothermia by definition is a condition in which the core body temperature drops below $35.0^{\circ} \mathrm{C}$ due to environmental factors. The effects of untreated hypothermia are systemic and include shock, altered mental status, arrhythmias including ventricular fibrillation, and coagulopathy. The changes are irreversible and lead to death [1]. 
The primary defensive mechanism is arteriovenous anastomoses, the closure of which results in reduced heat dissipation and muscular tremors, which in turn increases heat production by $50-100 \%$. Many factors affect the rate of hypothermia development. Among the causes of secondary hypothermia are, among others, severe trauma and shock, spinal cord rupture and lactic acidosis [2].

Analysing the case of a patient who suffered a severe injury, the greatest risk of hypothermia occurs at the prehospital stage. Such patients are often being found in the danger zone - for example, a car wreck. The evacuation of the victim from a vehicle often takes several dozen minutes and in the case of mountain accidents even several hours [3]. Interestingly, it has been shown that in the case of elderly victims of road accidents, it takes longer to evacuate and prepare for transport [4].

Alex et al. found that discomfort from cold became the most significant problem independent of their injury classification [5]. To reduce the adverse effects, active heating and proper thermal insulation should be provided at the pre-hospital stage. Active heating requires additional equipment. In scenarios with a large number of victims, this form of therapy may be challenging. Henriksson et al. highlighted the importance of thermal insulation during mass accidents or protracted evacuations in harsh conditions. Reduction of heat loss through evaporation can be achieved through wet clothing removal or the addition of a vapour barrier [6].

Supplementary oxygen treatment is recommended in Advanced Trauma Life Support (ATLS) [7] and International Trauma Life Support (ITLS) [8] manuals. Supplementary oxygen treatment is provided to prevent or correct hypoxaemia, as this may cause tissue hypoxia and organ failure. However, medical bags are usually stored in the back of emergency vehicles in unheated technical side compartments. Therefore, the temperature of the cylinder, and thus the oxygen, is balanced with the ambient temperature.

The guidelines for the treatment of patients with hypothermia indicated that oxygen therapy should be carried out using oxygen at a temperature of about $40^{\circ} \mathrm{C}$ [9]. At the moment, there are no devices available that would preheat oxygen to the recommended temperature in pre-hospital conditions, although this problem was already addressed in earlier work [10]. The last data review regarding the heating of inhaled gases comes from
1998 [11]. Over the last years, despite significant technological progress, this topic has not been developed.

The main objective of this initial report was to examine the influence of low ambient temperature on cooling oxygen in a rescue set and to check whether heating the oxygen tube with the rescuer's body is a legitimate method.

\section{METHODS}

\section{Ethical statement}

The study protocol has been approved by the Institutional Review Board of the Poznan University of Medical Sciences (KB No. 1053/18). Written consent has been obtained from the participant.

\section{Measurement technique}

The oxygen therapy kit consists of the following elements:

- 2.7 I white steel cylinder, in which 405 I of oxygen was compressed at 150 atm working pressure;

- Reducer with the possibility of setting the maximum oxygen flow of $25 \mathrm{l} / \mathrm{min}$,

- Non-bending catheters with a five-pointed star cross-section, $5 \mathrm{~mm}$ in diameter $(2.5 \mathrm{~m}$ long and $10 \mathrm{~m}$ long), supplying oxygen to the mask (Amsino International, Inc., Pomona, California, USA);

- Facial mask (Amsino International, Inc., Pomona, California, USA).

The FLIR T620 camera (FLIR Systems, Inc., Wilsonville, Oregon, USA) was used for thermographic measurements. The research was carried out in the winter in natural conditions that mapped the real working environment of the services.

Photographs were taken at regular intervals up to the point where no changes in the temperature distribution were observed. The elements of the measurement stand were cooled down until the ambient temperature was reached. When setting the measurement system and adjusting the oxygen flow rate during the test, cooled gloves were used to prevent the transfer of hand heat to the tested components.

All measurements were carried out in winter weather conditions: ambient temperature $-7.0^{\circ} \mathrm{C}$, low humidity, strong, frosty wind. Oxygen flow of $10 \mathrm{l} / \mathrm{min}$ was used, as recommended in ATLS and ITLS manuals [7, 8]. 
The thermal imaging camera was placed on a tripod approximately $2 \mathrm{~m}$ away from the measuring plate. To avoid artefacts on the thermograms, none of the measuring points was chosen on the paramedic's jacket.

The readings of the temperature were taken at the oxygen outlet from the cylinder $(\mathrm{Tc})$, at the outlet from the face mask $(\mathrm{Tm})$ and additionally during the measurements of the sample tested at the tube outlet from the jacket's sleeve (Ts).

\section{Description of the control test}

In the control test, the temperature of the components of the oxygen therapy kit was examined depending on the ambient conditions at the outflow from the cylinder. Figure 1 presents the measuring station. On the insulating board made of styrofoam, the oxygen therapy tubing was fixed in such a way to ensure the patency and constant diameter along its entire length. Two oxygen tubes of different lengths $(2.1 \mathrm{~m}$ and $10 \mathrm{~m})$ were used. The styrofoam plate was placed on two specially made wooden stands, ensuring the stability of the structure. A face mask was attached to the end of the oxygen tube, which was attached to the base to ensure a stable position and the possibility of observing the place of oxygen outlet from the mask. A cylinder with oxygen was placed next to the plate. Behind the plate and the cylinder, styrofoam shielding plates were additionally set, to limit the influence of radiation from other non-tested sources.

In the first variant whole set had an ambient temperature $\left(-7.0^{\circ} \mathrm{C}\right)$. In series I, a $10 \mathrm{~m}$ long tube

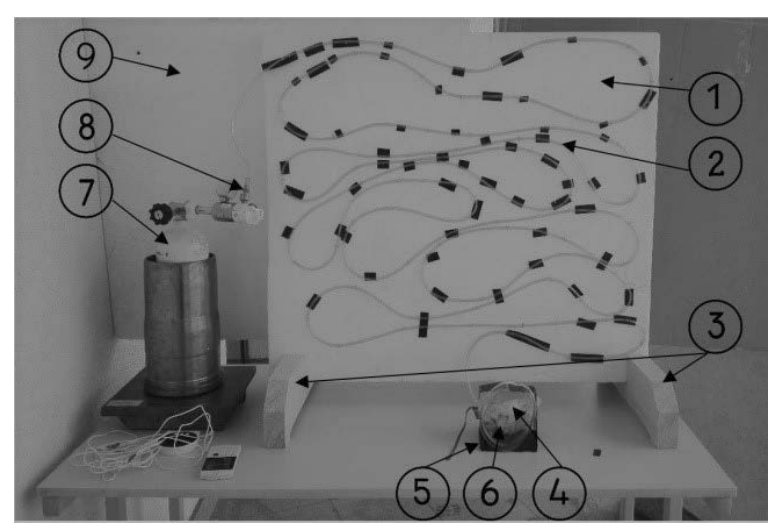

FIGURE 1. Measuring stands for the control test 1 - styrofoam board; 2 - oxygen tube; 3 - wooden stands; 4 - a face mask; 5 - base for the face mask; 6 - oxygen outlet; 7 - a cylinder with oxygen; 8 - oxygen outflow; 9 - styrofoam shielding plates has been used, and in series $112.1 \mathrm{~m}$ long. In the second variant, oxygen from a cylinder had $22.0^{\circ} \mathrm{C}$. In series III a $10 \mathrm{~m}$ tube was used and in the series IV - $2.1 \mathrm{~m}$ long tube.

\section{Description of the experimental test}

In the first test, the oxygen tube was heated through contact with the rescuer's body. The participant of the sample test was a Caucasian male with a bodyweight of $69 \mathrm{~kg}$ and $1.7 \mathrm{~m}$ height, wearing a jacket with a fleece lining, which is the emergency medical system employee's protective clothing (Fig. 2). The jacket was a fluorescent red colour entirely made of polyester with a polyurethane coating. Fleece lining made of polyester with a weight of $360-390 \mathrm{~g} / \mathrm{m}^{2}$.

Two variants of measurements were taken. In variant A [cold cylinder (CC)], the cylinder was cooled down to $-7.0^{\circ} \mathrm{C}$ (same as the ambient temperature). In variant $B$ [room temperature cylinder (RTC)], the cylinder had a temperature of $22.0^{\circ} \mathrm{C}$. The external conditions were identical to those in the control sample. The test was carried out until the temperature stabilized during a constant oxygen flow of $10 \mathrm{l} / \mathrm{min}$. Thermograms were recorded in one-minute intervals and the temperature was determined in three places: at the gas outlet from the cylinder $(T c)$, at the outlet of the oxygen tube from the jacket sleeve (Ts) and the oxygen outlet from the face mask (Tm). The block diagram of this system is shown in Figure 2.

\section{RESULTS}

\section{Control Test}

In the measurements taken in variant A (measurement I and II) change of temperature in time for tubes length $10 \mathrm{~m}$ and $2.1 \mathrm{~m}$ was illustrated. Results of this measurement showed a tendency of lowering down the temperature of both the face mask and the cylinder itself during the oxygen delivery. This process was not monotonic, which could be a credit to the influence of the surrounding. Amplitude in oxygen temperature is higher in the case of using the longer tube. Temperature decreases faster due to the bigger surface of heat exchange.

Surrounding settings in variant B were corresponding with the first series. The only difference was in the initial temperature of the set, which was $22.0^{\circ} \mathrm{C}$. Despite the temperature at the cylinder outlet being initially higher than the ambient 


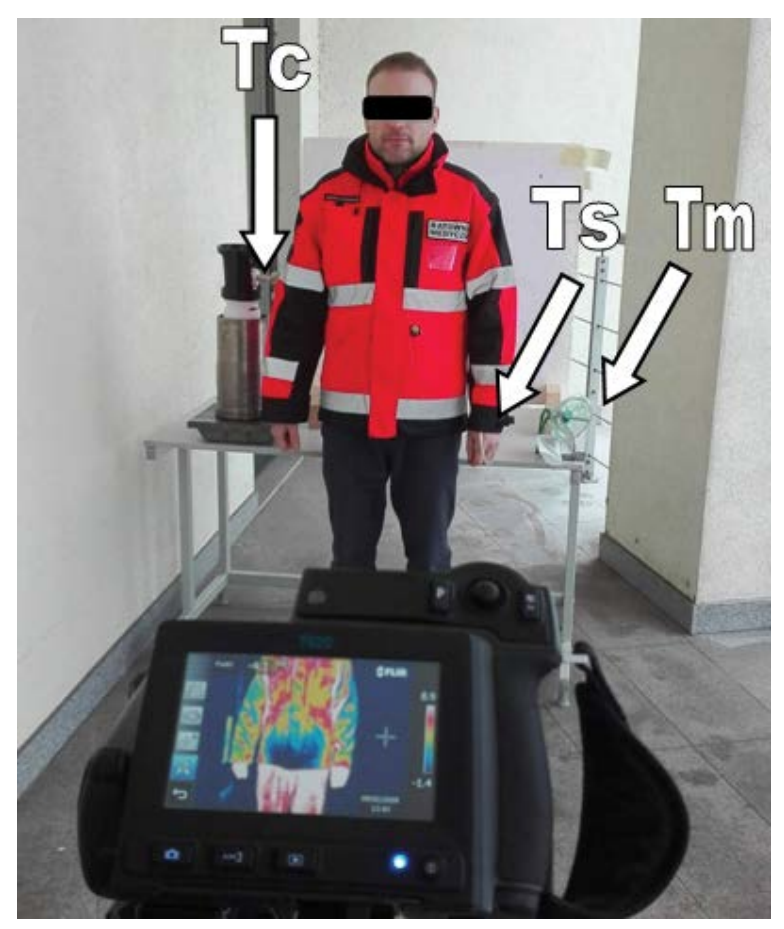

FIGURE 2. Measuring stand for the experimental tests Tc - The oxygen outlet from the cylinder; Ts - The outlet of the oxygen tube from the jacket sleeve; Tm - The oxygen outlet from the face mask

temperature, during the measurements, it was systematically decreasing, and after 3 minutes was close to an ambient temperature.

A similar effect was observed at the face mask outlet, where the final temperature of the mask after 5 min was equal to ambient temperature. In none of the measurements taken, the difference in temperature exceeded 1.0 degree.

Based on the measurements in the control test could be stated that the dynamics of temperature changes for a $2.1 \mathrm{~m}$ long tube is similar $10 \mathrm{~m}$ long tube. In both cases the temperature decreases. Due to the bigger surface of heat exchange, $10 \mathrm{~m}$ tube is more prone to an influence of surroundings, therefore it was the only tube used in further tests. The decision was made also based on the rescuer's possibilities of movement, as during the rescue action shorter tube $(2.1 \mathrm{~m})$ could be impeding the rescuer's moves.

\section{Experimental test}

In the CC variant, the temperature at the oxygen outflow point was $-6.0^{\circ} \mathrm{C}$ The highest temperature of the tube was obtained after the contact with the participant's body under the jacket $\left(6.9^{\circ} \mathrm{C}\right)$ when the tube was left. The increase in tube temperature

Table 1. The results of the experimental test
\begin{tabular}{|c|c|c|c|}
\hline \multicolumn{3}{|c|}{ Cold cylinder } & \multicolumn{2}{c|}{ Room temperature cylinder } \\
\hline $\max \Delta \mathrm{Ts}\left[{ }^{\circ} \mathrm{C}\right]$ & $\max \Delta \mathrm{Tm}\left[{ }^{\circ} \mathrm{C}\right]$ & $\max \Delta \mathrm{Ts}\left[{ }^{\circ} \mathrm{C}\right]$ & $\max \Delta \mathrm{Tm}\left[{ }^{\circ} \mathrm{C}\right]$ \\
\hline 12.9 & 8.9 & 8.0 & 4.0 \\
\hline
\end{tabular}

$\max \Delta \mathrm{Ts}$ - increase in temperature at the end of the jacket's sleeve; $\max \Delta \mathrm{Tm}$ - increase in mask temperature

after heating it under the paramedic's jacket was at least $12.9^{\circ} \mathrm{C}$. In the last $30 \mathrm{~cm}$ of the tube from the sleeve to the mask - the tube temperature dropped to $2.9^{\circ} \mathrm{C}$.

In the RC's variant, the temperature at the outlet of the warmed cylinder was higher than in a cool cylinder $-4.5^{\circ} \mathrm{C}$ ) At the end of the sleeve the temperature was positive (4.5), and on the mask, Tm was $0.5^{\circ} \mathrm{C}$. At the unisolated end of the tube (last $30 \mathrm{~cm}$ ), the oxygen temperature was dropping again for $4.0^{\circ} \mathrm{C}$. The results were presented in Table 1.

\section{DISCUSSION}

The results of this study indicate to increase in oxygen temperature due to warming under the rescuer's jacket. This beneficial effect, however, is partially reduced by cooling the oxygen on the last section of the tube in front of the mask. Regardless of the length of the tube, the supply of oxygen from a warm cylinder with a not insulated tube from a frosty environment does not guarantee the temperature of oxygen flowing out of the mask significantly higher than the ambient temperature.

The correct core body temperature is maintained in the range of $37 \pm 0.2^{\circ} \mathrm{C}[12]$. The human body exchanges heat with the environment using four mechanisms. These include radiation (loss of heat from $55-65 \%$ ), conduction (3\% of heat loss, but with direct contact with a cold surface can increase 32 times), convection ( $10 \%$ heat loss), evaporation ( $25 \%$ heat loss). Heat exchange during breathing is a process that consists partially of convection and evaporation. The amount of heat exchanged, in this case, depends on the temperature gradient between inhaled air and internal organs, the humidity of this air and respiratory rate [11]. The biggest loss occurs during ventilation with cold, dry air. It is estimated that the breathing process may be responsible for about $10 \%$ of the total heat loss [12]. To warm the gases inhaled from the environment, the body uses 2-9\% of heat [13].

Mild hypothermia initially results in stimulation of respiration and the occurrence of respiratory alka- 
losis. Further, a permanent reduction in tidal volume is proportional to the slowing down of the metabolism. Additionally, developing shock and electrolyte disturbances lead to the formation of acidosis. The ability of haemoglobin to bind oxygen is lower as compared to normothermia [14]. Fontanari et al. proved that inhalation of air at a temperature of $-4^{\circ} \mathrm{C}$ resulted in an increase of resistance in the airways by $17 \%$ and air at a temperature- $10^{\circ} \mathrm{C}$ by $42 \%$ [15]. It is one of the body's defence mechanisms against cold air, which is particularly unfavourable in patients with obstructive pulmonary diseases or heart failure. In a situation where the core temperature is lower than $34^{\circ} \mathrm{C}$, the frequency of epithelial cilia movement in the airway is significantly reduced, which in return impairs the ability to transport mucous $[16,17]$.

There is a fundamental difference between heating and thermal insulation. Heating is an active process. For it to exist, the principle must be fulfilled, so the temperature of the substance to be heated is higher than the current temperature of the body. The energy will be transmitted according to a gradient for example towards tissues. This process requires a tool that will be able to provide a constant supply of heat - for example, an electric fluid heater. Most of these devices require access to electricity or other permanent energy sources. Thermal insulation is a passive activity, in which the negative energy balance is leading to hypothermia can be slowed down by actions aimed at protecting the body against heat loss.

Williams et al. proved that heating oxygen up to $37.0^{\circ} \mathrm{C}$ and moisturizing it helps maintain the proper function of the mucous, its rheological properties. At the same time, this ensures the most effective work of the ciliary cells, which is necessary to maintain efficient and effective cleansing of the bronchial tree. At the same time, this temperature is not a thermal injury [18]. The risk of bronchospasm is also reduced and the patient's comfort is improved [19].

Hayward and Steinman have shown that the inhalation of warm gas increases the temperature measured on the eardrum membrane by $1.5^{\circ} \mathrm{C}$ for 30 minutes and also the rapid increase of the temperature in the oesophagus by $2.1{ }^{\circ} \mathrm{C}$ in the first 5 minutes. The obtained results were better than in the case of bathing in warm water [20]. Morrison et al. suggest that increasing the ventilation rate with heated air by $10 \mathrm{l} / \mathrm{min}$ causes an increase in core temperature by $0.3^{\circ} \mathrm{C} / \mathrm{h}[21]$.
Over the last 20 years, no scientific report has been made that would address the topic of heating gas in pre-hospital care. Perhaps the focus has been on improving other forms of hypothermia treatment that are more effective and can provide the patient with more heat in less time. The availability of methods based on extracorporeal circulation increases. Thanks to such methods, almost $60 \%$ survival is achieved in the group of patients with cardiac arrest or cardiogenic shock induced by hypothermia [22]. Such techniques - although very effective - are highly specialized procedures, available only in larger centres. Some authors suggest directly that the loss of heat in the process of breathing is so small that heating and humidifying the air cannot prevent the organism from losing heat [23]. In the authors' studies, oxygen was warmed by the rescuer's body heat. This method can be used in all conditions, does not require financial outlay and is simple. However, it was not effective enough to warm oxygen to a temperature higher than the human body - therefore it should be considered not in terms of heating but thermal insulation.

In 1998, a paper was published which described the use of warm oxygen inhalation in patients with deep hypothermia with cardiac arrest. The authors agreed that this may not be the only method of heating patients. It was also pointed out that it can be effectively used in prehospital treatment due to the lack of other more advanced heating techniques [10]. Information on various types of devices for heating and humidifying oxygen has been described by L. Lloyd. He pointed out, that the energy used to heat oxygen can be provided by a chemical reaction, the oxygen can be heated by burning gas or by-passing gas through a warm water bath heated by electricity [24]. Such a device must be small and light enough to be fitted into the basic rescue bag.

The results of research conducted in South Korea are also interesting. The authors have proved that in the operating room conditions, the use of a humidified and heated mixture of respiratory gases up to $37.0^{\circ} \mathrm{C}$ reduces the rate at which the core temperature falls. The results of these tests, therefore, confirm that heating oxygen can be effective thermal insulation [25]. However, there are many differences between the operating room's conditions and those in pre-hospital care. The hospital setting provides unrestricted access to external energy sources, which in pre-hospital conditions are limited and available only inside the ambulance. Also, diagnostic possibilities of measuring the core 
body temperature are smaller or less accurate. Only in a few ambulances, the equipment for taking core temperature measurements is available [26]. The priority in the hospital should be active heating complemented with thermal insulation. In pre-hospital care and especially during a difficult evacuation, heating is very difficult and sometimes impossible.

\section{Limitations}

This study has some limitations. The number of measurements was small. No statistical tests were used to find if the differences were significant and no confidence intervals were provided. In different countries, different types of clothing are used. The conclusions should only be applied to the clothing used in this study. The humans, and thus rescue service employees, are of different sizes and weights. So, it can not be expected that protection will always be equally effective. This procedure may be difficult to standardize and thus may be applicable only in limited situations. In addition, the main role of rescuers is to perform medical procedures and focusing on Warming oxygen may distract them from the more important issues. The aim of this paper was a preliminary assessment of the effectiveness of the presented method. The next stage will be studying assessing the actual effectiveness in preventing lowering body temperature. Despite the limitations, the authors, believe that this paper can be a form of a preliminary report presenting the possibilities of using simple methods to increase the effectiveness of rescue operations.

\section{CONCLUSIONS}

Placing the drain under the rescuer's jacket may prevent the oxygen from cooling down on the way from the cylinder to the oxygen mask. The use of the proposed method can improve the quality of thermal insulation and contribute to the improvement of treatment results in hypothermic patients in pre-hospital conditions. In optimal conditions, oxygen cylinders should be stored in a location that provides room temperature.

\section{ACKNOWLEDGMENTS}

The authors would like to thank Dr. Sylweriusz Kosiński, the expert in the field of hypothermia and intensive care for valuable tips and substantive help during the preparation of this manuscript.

\section{REFERENCES}

1. Chavala MLA, Gallardo MA, Martínez ÍS, et al. Management of accidental hypothermia: A narrative review. Medicina Intensiva (English Edition). 2019; 43(9): 556-568, doi: 10.1016/j.medine.2018.11.006.

2. Brown DJA, Brugger $H$, Boyd J, et al. Accidental hypothermia. N Engl J Med. 2012; 367(20): 1930-1938, doi: 10.1056/NEJMra1114208, indexed in Pubmed: 23150960.

3. Kosinski $S$, Darocha $T$, Jarosz $A$, et al. The longest persisting ventricular fibrillation with an excellent outcome - $6 \mathrm{~h} 45 \mathrm{~min}$ cardiac arrest. Resuscitation. 2016; 105: e21-e22, doi: 10.1016/j.resuscitation.2016.05.022, indexed in Pubmed: 27283064.

4. Fok P, Teubner D, Purdell-Lewis J, et al. Predictors of Prehospital On-Scene Time in an Australian Emergency Retrieval Service. Prehospital and Disaster Medicine. 2019; 34(03): 317-321, doi: 10.1017/ s1049023x19004394.

5. Henriksson 0 , Lundgren $P$, Kuklane $K$, et al. Protection against cold in prehospital care: evaporative heat loss reduction by wet clothing removal or the addition of a vapor barrier--a thermal manikin study. Prehosp Disaster Med. 2012; 27(1): 53-58, doi: 10.1017/ S1049023X12000210, indexed in Pubmed: 22445055.

6. Kosiński S, Darocha T, Sadowski J, et al. Hypothermia. Clinical Aspects of Body Cooling Analysis of Dangers Directions of Modern Treatment. 2016, doi: 10.4467/k9377.70/16.16.6987.

7. Paynter M. Trauma support: revolution in care. Emergency Nurse. 1993; 1(2): 7-9, doi: 10.7748/en.1.2.7.s2.

8. Collicott P. ADVANCED TRAUMA LIFE SUPPORT (ATLS). The Journal of Trauma: Injury, Infection, and Critical Care. 1992; 33(5): 749-753, doi: 10.1097/00005373-199211000-00026.

9. Kłosiewicz T, Zalewski R. Hipotermia pourazowa jako wyzwanie dla personelu zespołów ratownictwa medycznego. Pomeranian Journal of Life Sciences. 2018; 64(4), doi: 10.21164/pomjlifesci.484.

10. Weinberg $A D$. The role of inhalation rewarming in the early management of hypothermia. Resuscitation. 1998; 36(2): 101-104, doi: 10.1016/s0300-9572(98)00004-5, indexed in Pubmed: 9571725.

11. Błażejczyk K. Heat transfer between man and the environment in different geographic environments. Warsaw: Polish Academy of Sciences. ; 1993.

12. Sessler DI. Thermoregulatory defense mechanisms. Crit Care Med. 2009; 37(7 Suppl): S203-S210, doi: 10.1097/CCM.0b013e3181aa5568, indexed in Pubmed: 19535948.

13. Morrison JB, Conn ML, Hayes PA. Influence of respiratory heat transfer on thermogenesis and heat storage after cold immersion. Clin Sci (Lond). 1982; 63(2): 127-135, doi: 10.1042/cs0630127, indexed in Pubmed: 7083774.

14. Fisher $A$, Foëx $P$, Emerson $P M$, et al. Oxygen availability during hypothermic cardiopulmonary bypass. Crit Care Med. 1977; 5(3): 154-158, doi: 10.1097/00003246-197705000-00007, indexed in Pubmed: 16730.

15. Fontanari $P$, Zattara-Hartmann MC, Burnet $H$, et al. Changes in airway resistance induced by nasal inhalation of cold dry, dry, or moist air in normal individuals. J Appl Physiol (1985). 1996; 81(4): 1739-1743, doi: 10.1152/jappl.1996.81.4.1739, indexed in Pubmed: 8904594. 
16. Kilgour E, Rankin N, Ryan S, et al. Mucociliary function deteriorates in the clinical range of inspired air temperature and humidity. Intensive Care Med. 2004; 30(7): 1491-1494, doi: 10.1007/s00134-004-22353, indexed in Pubmed: 15024566.

17. Chidekel A, Zhu Y, Wang J, et al. The effects of gas humidification with high-flow nasal cannula on cultured human airway epithelial cells. Pulm Med. 2012; 2012: 380686, doi: 10.1155/2012/380686, indexed in Pubmed: 22988501.

18. Williams R, Rankin N, Smith T, et al. Relationship between the humidity and temperature of inspired gas and the function of the airway mucosa. Crit Care Med. 1996; 24(11): 1920-1929, doi: 10.1097/00003246199611000-00025, indexed in Pubmed: 8917046.

19. Richards GN, Cistulli PA, Ungar RG, et al. Mouth leak with nasal continuous positive airway pressure increases nasal airway resistance. Am J Respir Crit Care Med. 1996; 154(1): 182-186, doi: 10.1164/ ajrccm.154.1.8680678, indexed in Pubmed: 8680678.

20. Hayward JS, Steinman AM. Accidental hypothermia: an experimental study of inhalation rewarming. Aviat Space Environ Med. 1975; 46(10): 1236-1240, indexed in Pubmed: 1180782.

21. Morrison JB, Conn ML, Hayward JS. Thermal increment provided by inhalation rewarming from hypothermia. J Appl Physiol Respir
Environ Exerc Physiol. 1979; 46(6): 1061-1065, doi: 10.1152/jappl.1979.46.6.1061, indexed in Pubmed: 468624.

22. Darocha T, Kosinski S, Podsiadlo P, et al. EMS, HEMS, ECMO Center, ICU Team: Are You Ready for Hypothermic Patients?: Extracorporeal Membrane Oxygenation in Severe Accidental Hypothermia. JACC Heart Fail. 2016; 4(10): 829-830, doi: 10.1016/j.jchf.2016.07.008, indexed in Pubmed: 27686929.

23. Comparison of four intraoperative warming devices.Ouellette RG. AANA J. 1993; 61: 394-396.

24. Lloyd E. Equipment for airway warming in the treatment of accidental hypothermia. Journal of Wilderness Medicine. 1991; 2(4): 330-350, doi: 10.1580/0953-9859-2.4.330.

25. Park HJ, Moon HoS, Moon SeHo, et al. The effect of humidified heated breathing circuit on core body temperature in perioperative hypothermia during thyroid surgery. Int J Med Sci. 2017; 14(8): 791-797, doi: 10.7150/ijms. 19318, indexed in Pubmed: 28824315.

26. Karlsen AM, Thomassen 0 , Vikenes BH, et al. Equipment to prevent, diagnose, and treat hypothermia: a survey of Norwegian pre-hospital services. Scand J Trauma Resusc Emerg Med. 2013; 21: 63, doi: 10.1186/1757-7241-21-63, indexed in Pubmed: 23938145. 